\title{
Efficacy of Silver Nanoparticles as Antimicrobial Agent against Salmonella Infection and Accompanied Biochemical, Immunological and Histopathological Changes in Rats
}

\author{
Mohamed A. Abd-Elhakeem ${ }^{1}$, Ingy Badawy ${ }^{1 *}$ and Amira Raafat ${ }^{2}$ \\ ${ }^{l}$ College of Biotechnology, Misr University for Science and Technology, Giza, Egypt, \\ ${ }^{2}$ National Cancer Institute, Cairo, Egypt.
}

\section{ARTICLE INFO}

Article history:

Received 17 March 2016

Accepted 17 April 2016

Keywords:

Salmonella;

Silver nanoparticles;

Digestive tract infection.

\begin{abstract}
A B S T R A C T
Antimicrobial activity of silver nanoparticles against Salmonella typhimurium was investigated under both in vitro and in vivo conditions. Salmonella typhimurium-infected rats were used for this study. The infection and treatment were followed by biochemical analysis [liver and kidney functions, immunoglobulins (IgM, IgG and $\operatorname{IgA}$ )], in addition to histopathological examination of liver, kidney, small intestine and stomach. Results revealed that silver nanoparticles had a significant effect on reducing the number of viable Salmonella typhimurium, recovered from faeces, and could stop salmonellosis after five to six days of treatment. The biochemical analyses showed no characteristic difference between the control and all studied groups regarding the liver function tests (ALT, AST, ALP and albumin) and the kidney function tests (urea and creatinine). The immunoglobulins $\operatorname{IgA}$ and IgM levels were significantly changed during treatment. The histopathological analyses showed presence of an obvious inflammation, hemorrhage and some necrotic cells in all tested organs of infected rats. After treatment with AgNPs the inflammation was significantly decreased. Therefore it could be concluded that silver nanoparticles within the used dose and time have high efficacy against S. typhimurium digestive tract infection without noticeable toxicity.
\end{abstract}

\section{Introduction}

Salmonella enterica is rod shaped Gram negative bacterial pathogen capable of infecting humans and animals, cause significant morbidity and mortality worldwide ${ }^{[1]}$.Certain serotypes adapted tohuman, such as Salmonella typhi (S. typhi) and Salmonella paratyphi (S. paratyphi), usually cause severe diseases ${ }^{[2]}$. Ingestion of food contaminated with Salmonella typhi gives rise to infection of the small intestine and to gastroenteritis that could be developed to typhoid fever [3]. Symptoms of infection include nausea, vomiting, abdominal cramps, diarrhea, fever and headache. In chronic cases, arthritis symptoms may follow 3 to 4 weeks after the onset of acute symptoms ${ }^{[4]}$. The infection is normally treated using antibiotics such as chloromycetin, ampicillin, amoxicillin, and ciprofloxacin ${ }^{[5]}$. However, S. typhi, has rapidly gained resistance to the previously efficacious drugs. Hence, there is a need for new anti-typhoid agents.

\footnotetext{
* Corresponding author.

E-mail address: inji.mahmoud@must.edu.eg
}

Silver ion has been used as antiseptic agent for more than a century ${ }^{[6]}$. As a result of nanotechnology rising, silver nanoparticles (AgNPs) have attracted considerable attention as antimicrobial agents ${ }^{[7]}$. Despite the rapidly growing presence of silver-containing products on the market ${ }^{[8]}$ and extensively studies about antimicrobial activity of AgNPs ${ }^{[9-11]}$, there is only limited information about the usage of AgNPs as a therapeutic agent in vivo. In a previous study ${ }^{[12]}$, the authers studied the efficiency of silver nanoparticles formulated cream against dermal infection caused by Staphylococcus aureus. The results showed high antibacterial activity of our cream with no obvious skin-histological change. The promised results of the topical usage encouraged us to examine the antimicrobial activity of AgNPs on a systematic level. So, this study aims to investigate the therapeutic potentials of AgNPs for the treatment of digestive tract infection caused by Salmonella and the accompanied possible side effects via biochemical analyses (liver enzymes level, kidney function tests and immunoglobulins) and histopathological imaging of the liver, kidney, stomach and small intestine. 


\section{Materials and Methods}

Silver nitrate and trisodium citrate were purchased from Sigma Aldrich Co. All diagnostic kits were purchased from Diamond Diagnostic (Cairo, Egypt). Salmonella typhimurium was used in this study and was kindly obtained from Prof. Dr. Azza Abu Zeid (Professor of Microbiology, Faculty of Science, Zagazig University). Bacterial strain was maintained on agar slant at $4^{\circ} \mathrm{C}$ and sub-cultured on a fresh appropriate agar plate $24 \mathrm{~h}$ prior to antimicrobial test. Salmonella-Shigella agar plates were used for the activation of Salmonella, and during in vivo assays in rats for bacterial counts and identification. All microbiological tests were performed at Research and Development Center, Misr University for Science and Technology.

\section{Preparation of silver nanoparticles}

Silver nanoparticles were prepared through a chemical reduction route by reduction of aqueous silver nitrate with sodium citrate at boiling temperature. In typical procedure, $20-\mathrm{mL}$ aqueous solution of $1 \%$ sodium citrate was added dropwise to a $100-\mathrm{mL}$ aqueous solution of $0.001 \mathrm{M}$ silver nitrate. The mixture was heated to the boiling with continuous stirring. The formation of yellow colored solution indicates the presence of AgNPs. The yielded particles were collected by centrifugation then washed with absolute ethanol, dried and saved for the next step at room temperature.

\section{Antimicrobial activity of AgNPs}

The well diffusion method was used to evaluate the antibacterial activity of silver nanoparticles. Solutions of different concentrations of AgNPs $(0-150 \mu \mathrm{g} / \mathrm{ml})$ in distilled water was prepared. Nine $\mathrm{ml}$ Petri dishes containing sterilized media were separately inoculated with bacterial suspension $\left(10^{4} \mathrm{CFU} / \mathrm{ml}\right)$. After media solidification $1 \mathrm{ml}$ diameter wells were punched by sterile gel puncher and immediately filled by $100 \mu \mathrm{l}$ of AgNPs solution. The plates were incubated at $37^{\circ} \mathrm{C}$ for 24 hours; the antimicrobial activity was assessed by measuring the diameter of inhibition zone around each well.

\section{Animals and condition}

Three-month old female Sprague-Dawley rats (160180) $\mathrm{g}$, were purchased from the animal house colony, $6^{\text {th }}$ October city, Egypt. The animals were housed in specially designed cages (five rats per cage) and maintained on standard lab diet (protein: 160.4; fat: 36.3; fiber: $41 \mathrm{~g} / \mathrm{kg}$ and metabolizable energy of 12.08 $\mathrm{MJ})$. All rats were housed in a room free from any source of chemical contamination, artificially illuminated and thermally controlled at the Animal House Lab., Pharmacology and Chemistry Research Centre, Misr University for Science and Technology. The animals have received human care in compliance with the ethical guidelines of the Animal Care and Use Committee of the Pharmacology and Chemistry Research Centre ${ }^{[13]}$.

\section{Infection Model}

The induction of infection was carried out according to the methods as described by Talaet al., ${ }^{[14]}$. Typically, rats were fasted overnight and given, by gavage, $1 \mathrm{ml}$ of saline solution $(0.9 \% \mathrm{NaCl})$ containing $1.5 \times 10^{8} \mathrm{CFU}$ of Salmonella typhimurium. After four days, fresh faecal samples were collected to quantify Salmonella colonisation daily. Faeces collected were dissolved in saline $(0.9 \% \mathrm{NaCl})$ at the proportion of $1 \mathrm{~g}$ for $2 \mathrm{ml}$ of suspension. Aliquots $(100 \mu \mathrm{L})$ of faecal suspensions were serially diluted in saline $(0.9 \% \mathrm{NaCl})$ and then plated on duplicate Salmonella-Shigella agar plates, which were subsequently incubated overnight at $37^{\circ} \mathrm{C}$. Typical colonies were then identified and counted on the plates. A steady increase in the bacterial load during the four days indicated the establishment of the infection. After salmonellosis was confirmed, infected rats were used in the current study.

\section{Experimental design:}

Rats were randomly divided into four groups (ten rats for each). Group (I), animals were infected and not treated; Group (II), animals were infected then treated orally with AgNPs (10 mg/ kg); Group (III), healthy animals that not infected and receive only AgNPs solution $(10 \mathrm{mg} / \mathrm{kg}$ ) during the treatment period in addition to ten healthy rats as control that receive distilled water. At the end of the treatment period, the biochemical, and histopathological markers were evaluated in rats using standard methods and kits.

\section{Blood sampling:}

Rats under investigation were anaesthetized using diethyl ether, then animals were dissected and their blood was collected from the hepatic portal vein. Blood samples were collected in tubes and immediately centrifuged at $3,000 \mathrm{rpm}$ for $15 \mathrm{~min}$ to separate blood serum. The separated serum was sampled into clean tubes and kept in $-20^{\circ} \mathrm{C}$ for subsequent analysis.

\section{Biochemical analysis:}

The following parameters were determined in serum samples using the proper kit: aspartate aminotransferase (AST), alanine aminotransferase (ALT), alkaline phosphatase (ALP), urea and creatinine. In addition to the immunoglobulins (IgG, $\operatorname{IgA}$ and $\operatorname{IgM}$ ) using radial immunodiffusion assay.

\section{Histopathology of different organs}

Tissue cross sections were prepared and analyzed using conventional techniques. Briefly, after sacrificing the animals, small pieces of liver, kidney, stomach, and intestine were collected and immediately preserved in the fixation solution $\left(900 \mathrm{ml}\right.$ water, $6.5 \mathrm{~g} \mathrm{Na}_{2} \mathrm{HPO}_{4}, 4 \mathrm{~g}$ $\mathrm{NaH}_{2} \mathrm{PO}_{4}, 100 \mathrm{ml} 40 \%$ formalin). The fixed tissue were embedded in paraffin wax and sectioned into five micrometres thick with the rotary microtome, then stained with hematoxylin and eosin. Then the sections were examined with light microscope and photographed using a microscopic camera.

\section{Statistical analysis}

Data were expressed as mean $\pm \mathrm{SD}$. The two-tailed Student's $t$-test was used to compare means of different groups. P-value of $<0.05$ was considered statistically significant. 


\section{Results and discussion}

Synthesis and characterization of silver nanoparticles The colloidal AgNPs suspended in the aqueous medium pose dark yellow color at the end of reduction process due to Surface Plasmon Resonance (SPR) ${ }^{[15]}$. In general AgNPs strongly absorb radiation near wavelengths of $400 \mathrm{~nm}$. Figure (1) shows the UV-Vis spectrum of AgNPs solution (UV/VIS spectrophotometer, Shimadzu UV1800) with $\lambda_{\max }$ at $410 \mathrm{~nm}$. Further, the size of AgNPs was determined by using Transmission Electron Microscope (TEM) (JEOL JAM-2100-HR-EM; National Research Centre, Giza, Egypt). Results revealed spherical shaped particles in a broad size distribution from 15 to $60 \mathrm{~nm}$ with an average size of $40 \mathrm{~nm}$ Figure (2).

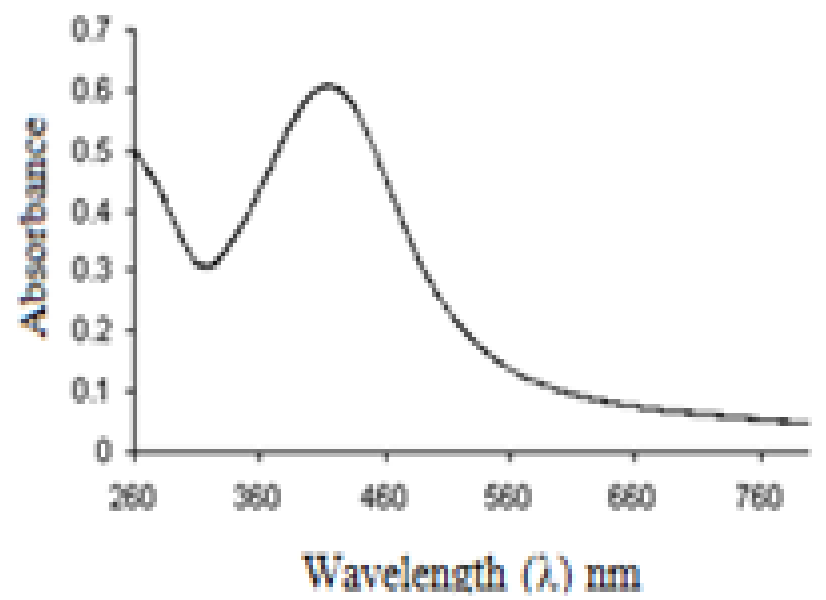

Fig (1): UV-Vis absorption spectrum of AgNPs

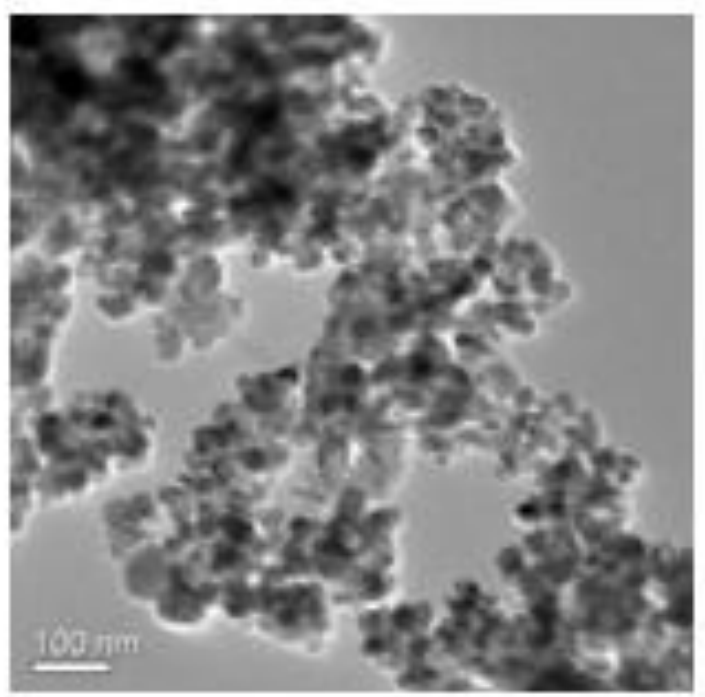

Fig (2): TEM image of AgNPs.

In vitro antimicrobial activity of AgNPs against Salmonella typhimurium

Salmonella typhimurium induces a systemic infection in mice and rats (similar to that induced by $S$. typhi in humans). Thus, salmonellosis prompted by $S$. typhimurium in rats has many similarities to the typhoid fever in human, so $S$. typhimurium-infected rats or mice have been widely utilized as models for understanding of the pathophysiology of typhoid fever ${ }^{[16]}$. The lowest concentration that completely inhibited visible growth or the minimum inhibitory concentration (MIC) of AgNPs against $S$. typhimurium was $100 \mu \mathrm{g} / \mathrm{ml}$. However, 50 $\mu \mathrm{g} / \mathrm{ml}$ AgNPs showed only slight inhibition.

\section{In vivo antibacterial activity of AgNPs in rats}

In general, the number of viable $S$. typhimurium recovered from faeces increased during the first day following the infection. The administration of AgNPs solution (group II) was found to induce marked decreases on the number of viable $S$. typhimurium recovered from faeces. Between the fifth and sixth days of the treatment period, rats did not shed any viable $S$. typhimurium in faeces. The number of viable $S$. typhimurium didn't decrease in the faeces of infected and untreated animals (group I), during the treatment period.

\section{General morphological findings in rats}

Weights of all animals were recorded continuously until the end of this study. There are no observed statistically significant $(P>0.05)$ changes between all groups with respect to body weight at any time (data not shown). Also, no significant differences were recorded in food and water consumption of animals during this study. Finally, the relative organ weights of liver, kidney and spleen did not show any significant $(P>0.05)$ differences between the treated groups and the control group (data not shown).

\section{Biochemical analysis}

Results also showed no characteristic difference between the control and all studied groups regarding the liver function tests (ALT, AST, ALP and albumin) and the kidney function tests (urea and creatinine), Table (1), meaning that AgNPs within the used dose and time don't have hepatic or renal toxicity.

\section{Immunoglobulins}

The primary function of the immune system is to detect and recognize foreign substances in order to protect the host. Nanoparticles can either interfere with this function or themselves be recognized as foreign antigens and thus elicit immune response ${ }^{[17]}$. A disturbance in the immune system can lead to severe medical conditions ${ }^{[18]}$. Studying the effect of AgNPs on humoral immunity may play a great role in understanding the possible risks of using AgNPs in therapeutical applications. Some nanoparticles have an epitope structure to which specific antibodies bind. Being small molecules by definition however, most nanoparticles probably act as haptens, which are immunogenic only when attached to a larger carrier molecule. Chen et al. ${ }^{[19]}$ demonstrated that the immune system can generate antibodies specific to nanoparticles. 
Results presented in Table (1) indicated that the level of serum IgG was decreased in all studied groups as compared with control group, while there is no significance change between the infected group before and after treatment by AgNPs. This may be due to the fact that $\operatorname{IgG}$ is the antibody in the secondary immune response which is mediated by the memory B-Cells that for what it didn't increase after the first infection.

In contrast, IgM is the first antibody produced by the $\beta$ lymphocytes in the early stage of an immune response (primary immune response) which acts as agglutinating bodies that clamp microorganisms for eventual elimination from the body. A study done on rats showed an increase in IgM and IgE serum levels after treatment with both $20 \mathrm{~nm}$ and $100 \mathrm{~nm} \mathrm{Ag-NP}{ }^{[20]}$. Our results showed a significant increase of IgM level in group (I) $(\mathbf{8 2 . 1 0} \pm \mathbf{1 . 8 0} \mathrm{mg} / \mathrm{dl})$ in comparison with control group
$(51.35 \pm 4.20 \mathrm{mg} / \mathrm{dl})$ that reveals the immune response to the bacterial infection. After treatment with AgNPs (group II), the IgM level was recovered to the normal

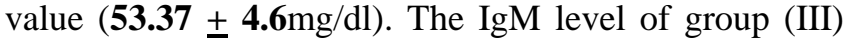
showed also significant increase $(89.97 \pm \mathbf{4 . 0 1} \mathrm{mg} / \mathrm{dl})$, which means that AgNPs may stimulate the IgM level, which may enhance their antimicrobial activity.

Finally, IgA is the immunoglobulins found essentially in secretions of respiratory system and gastrointestinal tract. The results showed that, there is a significant increase in serum level of IgA in group II as compared with control $(218.01 \pm \mathbf{1 0 . 0 8}, 115.17 \pm \mathbf{6 . 0 5} \mathrm{mg} / \mathrm{dl})$, respectively, while $\overline{i t}$ remained unchanged after administration of AgNPs only (group III), which might support the nontoxicity of AgNPs.

Table 1: Effect of Salmonella infection and AgNPs treatment on biochemical markers and immunoglobulin levels in rats.

\begin{tabular}{l||lllll}
\hline Item & Unit & Control & $\begin{array}{l}\text { Group I } \\
\text { (Infected) }\end{array}$ & $\begin{array}{l}\text { Group II } \\
\text { (Infected and treated) }\end{array}$ & $\begin{array}{l}\text { Group III } \\
\text { (Ag only) }\end{array}$ \\
\hline \hline IgM & mg/dl & $51.35 \pm 4.20$ & $82.10 \pm 1.80^{*}$ & $53.37 \pm 4.6$ & $89.97 \pm 4.01^{*}$ \\
IgA & $\mathrm{mg} / \mathrm{dl}$ & $115.17 \pm 6.05$ & $218.01 \pm 10.08^{*}$ & $91.83 \pm 5.45$ & $123.69 \pm 4.85$ \\
IgG & $\mathrm{mg} / \mathrm{dl}$ & $3295.47 \pm 279.8$ & $2568.66 \pm 141.66^{*}$ & $2783.15 \pm 147.01^{*}$ & $2175.37 \pm 73.21^{*}$ \\
\hline \hline Albumin & $\mathrm{g} / \mathrm{dl}$ & $2.66 \pm 0.10$ & $2.64 \pm 0.10$ & $2.75 \pm 0.11$ & $2.74 \pm 0.13$ \\
$\mathrm{ALP}$ & $\mathrm{U} / \mathrm{dl}$ & $229.73 \pm 50.79$ & $237.14 \pm 52.27$ & $234.63 \pm 51.31$ & $245.68 \pm 48.78$ \\
AST & $\mathrm{U} / \mathrm{dl}$ & $7.75 \pm 0.43$ & $7.00 \pm 0.21$ & $7.00 \pm 0.40$ & $8.50 \pm 0.33$ \\
ALT & $\mathrm{U} / \mathrm{dl}$ & $58.25 \pm 1.42$ & $48.00 \pm 1.12$ & $52.00 \pm 1.65$ & $67.75 \pm 1.87$ \\
Urea & $\mathrm{mg} / \mathrm{dl}$ & $45.96 \pm 0.91$ & $53.48 \pm 1.24$ & $40.85 \pm 0.75$ & $41.88 \pm 0.97$ \\
Creatinine & $\mathrm{mg} / \mathrm{dl}$ & $0.55 \pm 0.07$ & $0.51 \pm 0.05$ & $0.53 \pm 0.06$ & $0.58 \pm 0.04$ \\
\hline \hline
\end{tabular}

Values are mean \pm SD of 5 determinations. ${ }^{*}$ Significantly different from values of control group at $\mathrm{p}<0 \_05$.

\section{Histopathology:}

Histology of the different organs of the control group shows the normal cells withwell-preserved cytoplasm, prominent nucleus (Figures 3a, 4a, 5a). An obvious inflammation and hemorrhage and some necrotic cells were observed in all organs of group (I) rats (Figures $\mathbf{3 b}, \mathbf{4 b}, \mathbf{5 b}$ ). After treatment with AgNPs for six days the inflammation was significantly decreased and recovered to the normal structure (Figures $3 \mathbf{c}, \mathbf{4 c}, \mathbf{5 c}$ ).

\section{Conclusion:}

The overall results of the current work provide baseline information for the possible use of the AgNPs in the treatment of salmonellosis, especially typhoid fever. In vitro, AgNPs showed high antimicrobial activity with
MIC equal $100 \mu \mathrm{g} / \mathrm{ml}$. Moreover, the in vivo antibacterial activity revealed that the administration of $10 \mathrm{mg} / \mathrm{Kg}$ of AgNPs for five to six days plays a great role in Salmonella typhimurium treatment without any obvious hepatic or renal toxicity.In addition to antibacterial activity and nontoxicity, AgNPs stimulate IgM levels which may help in healing efficiency. So AgNPs may be considered as relatively safe drug for Salmonella typhimurium treatment within the same dose and time. In order to ensure safe use of nanosized particles, further studies should focus on how their physical and chemical properties can influence their interaction with the immune system either through activation or modulation of the immune response 


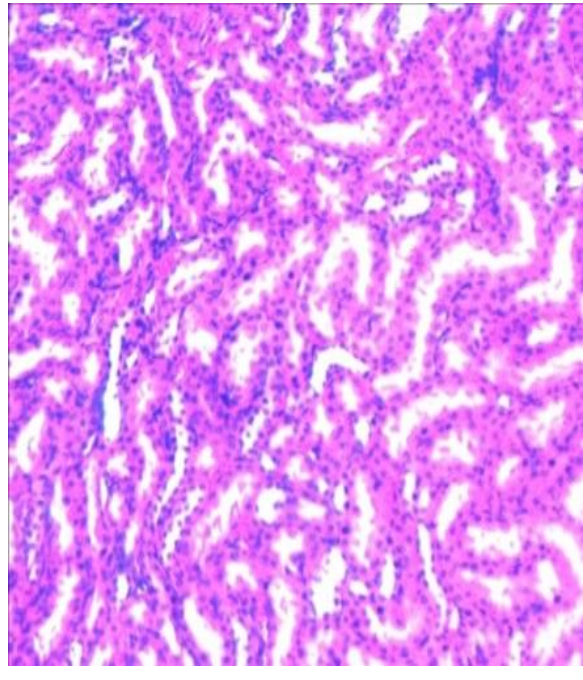

a

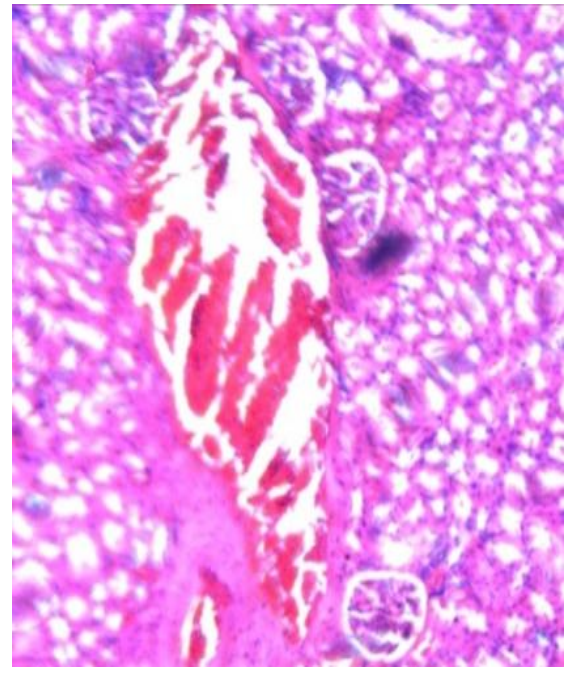

b

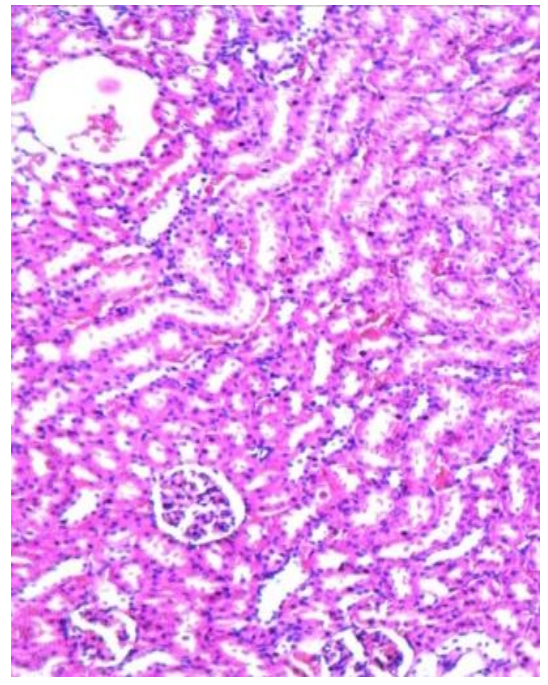

$\mathrm{C}$

Fig. (3): (a), H\&E stained section of normal kidney showing normal tubules, 10X. (b), H\&E stained section of Salmonella infected kidney showing area of hemorrhage and degeneration of tubules, 40X. (c), H\&E stained section of kidney showing no hemorrhage and disappearance of degeneration, 40X.

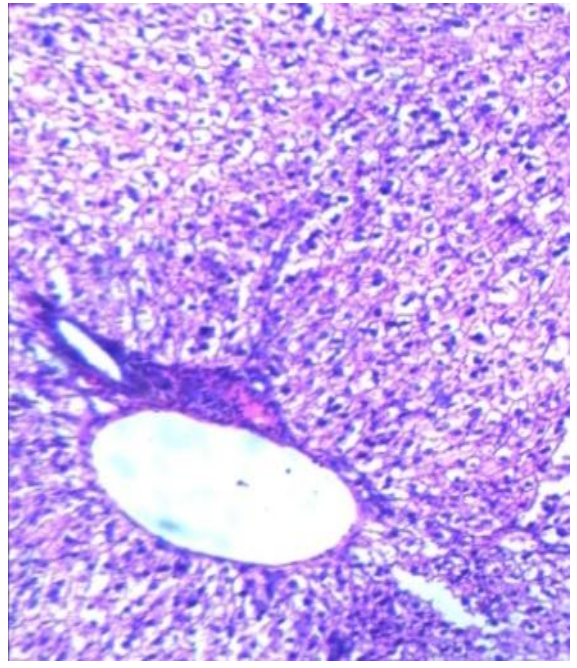

$\mathrm{a}$

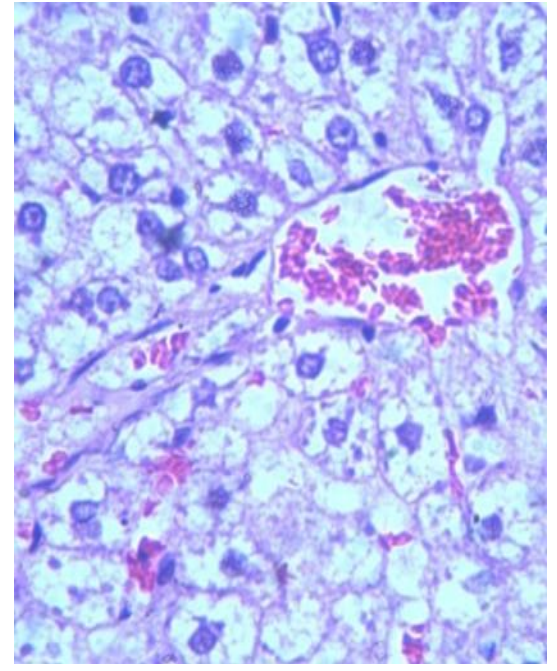

b

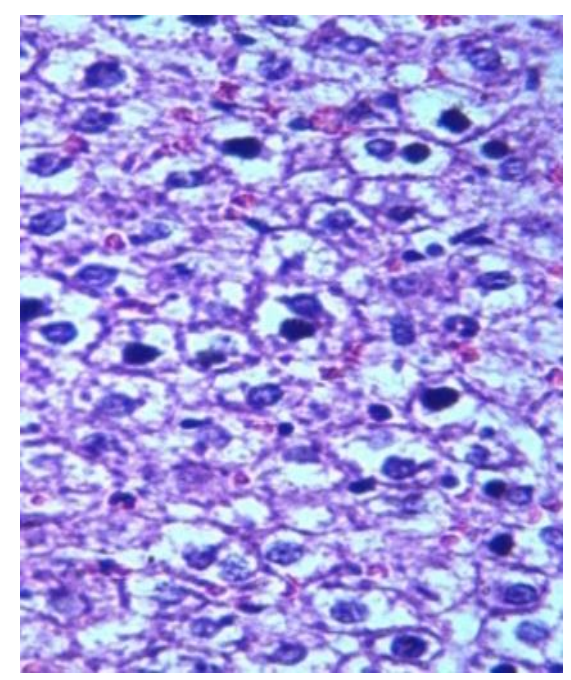

c

Fig. (4): (a), H\&E stained section of normal liver showing central vein and normal hepatocytes, 10X. (b), H\&E stained section of liver infected with Salmonella, showing areas of hemorrhage and hydropic degeneration of cells, 40X. (c), H\&E stained section of liver showing decrease area of hemorrhage and decrease hydropic degeneration of cells, 40X. 


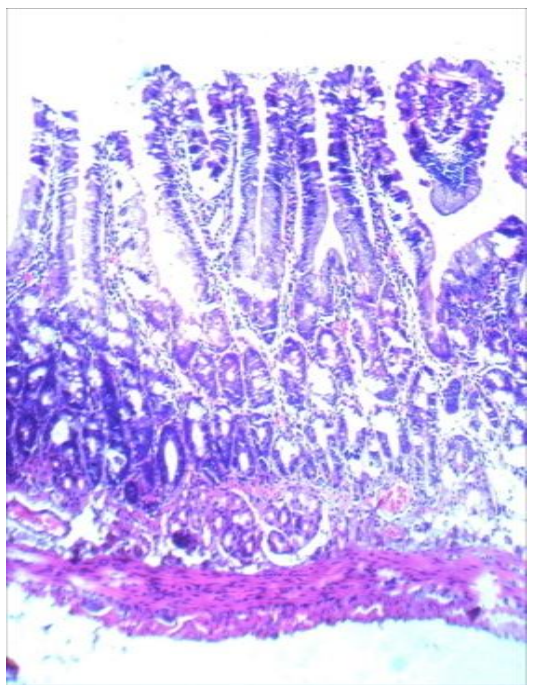

a

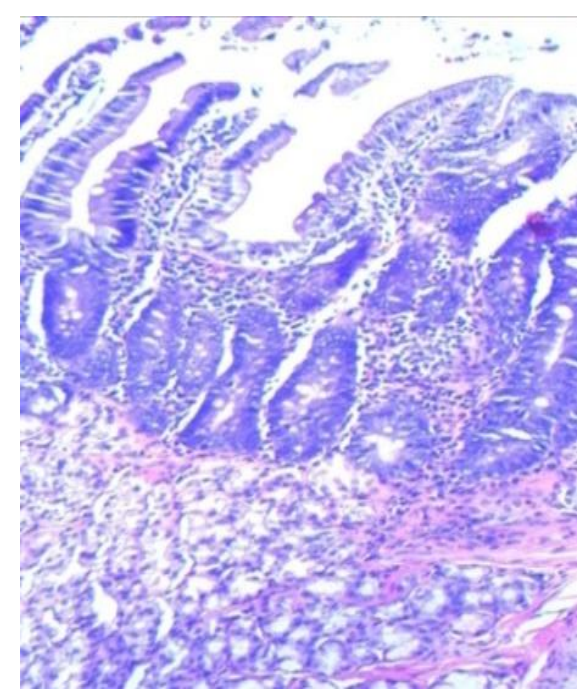

b

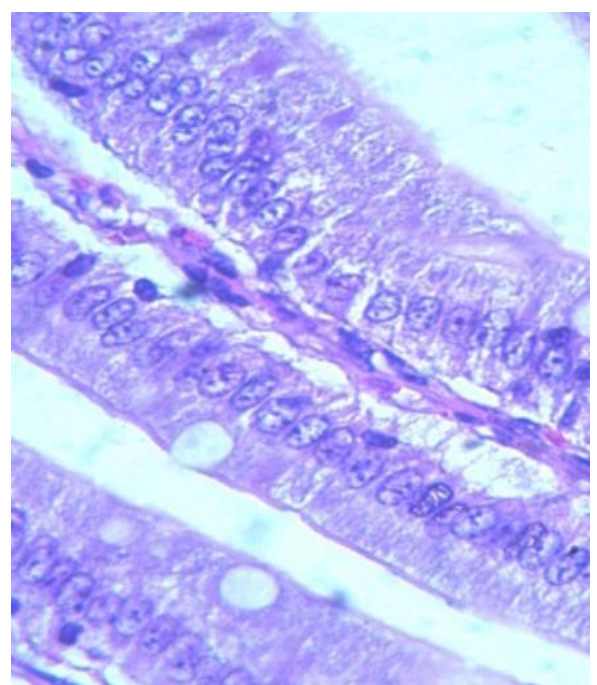

c

Fig. (5): (a), H\&E stained section of stomach, showing normal gastric glands, 40X. (b), H\&E stained section of stomach showing inflammatory cells between gastric glands, 40X. (c) H\&E stained section of stomach showing decreased of inflammation between gastric cells, $40 \mathrm{X}$.

\section{References}

1) Chuanchuen, R. and Padungtod, P. (2009). Antimicrobial resistance genes in Salmonella enterica isolates from poultry and swine in Thailand. J Vet Med Sci., 71(10): 1349-1355.

2) Bjo" rkman, J., Hughes, D. and Andersson, D. I. (1998). Virulence of antibiotic-resistant Salmonella typhimurium. Proc. Natl. Acad. Sci. USA, 95: 39493953.

3) Adebolu, T. T., Adeoye, O. O. and Oyetayo, V. O. (2011). Effect of garlic (Allium sativum) on Salmonella typhi infection, gastrointestinal flora and hematological parameters of albino rats. African Journal of Biotechnology, 10(35): 6804-6808.

4) Adeyi, A. O., Jinadu, A. M., Arojojoye, O. A., Alao, O. O., Ighodaro, O. M. and Adeyi, O. E. (2013). In vivo and in vitro antibacterial activities of Momordicacharantia on Salmonella typhi and its effect on liver function in typhoid-infected rats. Journal of Pharmacognosy and Phytotherapy, 5(11): 183-188.

5) Rotimi, S. O., Ojo, D. A., Talabi, O. A., Balogun, E. A. and Ademuyiwa, O. (2012). Tissue dyslipidaemia in Salmonella-infected rats treated with amoxillin and pefloxacin. Lipids in Health and Disease, 11: 152-163.

6) Costanza, J., El Badawy, A. M. and Tolaymat, T. M. (2011). Comment on "120 Years of nanosilver History: Implications for Policy Makers". Environ Sci. Technol., 45(17): 7591-7592.
7) Han, D. W., Woo, Y. I., Lee, M. H., Lee, J. H., Lee, J. and Park, J. C. (2012). In vivo and in vitro biocompatibility evaluations of silver nanoparticles with antimicrobial activity. J. Nanosci. Nanotechnol., 12: 5205-5209.

8) Jain, J., Arora, S., Rajwade, J. M., Omray, P., Khandelwal, S. and Paknikar, K. M. (2009). Silver Nanoparticles in Therapeutics: Development of an Antimicrobial Gel Formulation for Topical Use. Molecular Pharmaceutics, 6(5): 1388-1401.

9) Grigor'eva, A., Saranina, I., Tikunova, N., Safonov, A., Timoshenko, N., Rebrov, A. and Ryabchikova, E. (2013). Fine mechanisms of the interaction of silver nanoparticles with the cells of Salmonella typhimurium and Staphylococcus aureus. Biometals, 26: 479-488.

10) Chernousova, S. and Epple, M. (2013). Silver as antibacterial agent: ion, nanoparticle, and metal. Angew. Chem. Int. Ed. Engl., 52(6): 1636-1653.

11) Choia, O., Dengb, K. K., Kimc, N., Jr, L. R., Surampallie, R. Y. and Hu, Z. (2008). The inhibitory effects of silver nanoparticles, silver ions, and silver chloride colloids on microbial growth. Water Res., 42(12): 3066-3074.

12) Abd-Elhakeem, M. A., Badawy, I., Hamzawy, M. A., Raafat, A., Elsayed, A. M., Nadim, M., Zaher, A. and Shahin, A. (2014). Antimicrobial activity and cytotoxicity of silver nanoparticles formulated cream against Staphylococcus aureus dermal infection in albino rats. Journal of Nanopharmaceutics and Drug Delivery, 2: 235-239. 
13) Guide to the care and use of experimental animals, Canadian council on animal care (CCAC), Canada, 1993, volume 1 ( $2^{\text {nd }}$ edition).

14) Tala, D. S., Gatsing, D., Pierre, S., Fodouop, C., Fokunang, C., Kengni, F. and Djimeli, M. N. (2015). In vivo anti-Salmonella activity of aqueous extract of Euphorbia prostrate Aiton (Euphorbiaceae) and its toxicological evaluation. Asian Pac J. Trop. Biomed., 5(4): 310-318.

15) Suez, J., Porwollik, S., Dagan, A., Marzel, A., Schorr, Y. I. and Desai, P. T. (2013). Virulence gene profiling and pathogenicity characterization of nontyphoidal Salmonella accounted for invasive disease in humans. PLosOne, 8(3): 58449-58470.

16) Song, J., Willinger, T., Rongvaux, A., Eynon, E. E., Stevens, S., Manz, M. G., Flavell, R. A. and Galán, J. E. (2010). A mouse model for the human pathogen Salmonella typhi. Cell Host Microbe, 8(4): 369-376.
17) Klippstein, R., Fernandez-Montesinos, R., Castillo, P. M., Zaderenko, A. P. and Pozo, D. (2010). Silver nanoparticles interactions with the immune system: implications for health and disease. In: Pozo Perez D, editor. Silver nanoparticles. $1^{\text {st }}$ ed. Rijeka: In Tech Open; p. 309-324.

18) Glaser, R. and Kiecolt-Glaser, J. K. (2005). Stressinduced immune dysfunction: implications for health. Nat Rev Immunol., 5: 243-251.

19) Chen, B. X., Wilson, S. R, Das, N., Coughlin, D. J. and Erlanger, B. F. (1998). Antigenicity of fullerenes: Antibodies specific for fullerenes and their characteristics. Proc Natl Acad Sci USA, 95: 10809-10813.

20) De Jong, W. H., Van Der Ven, L. T. M., Sleijffers, A., Park, M. V. D. Z., Jansen, E. H. J. M., Loveren, H. V. and Vandebriel, R. J. (2013). Systemic and immunotoxicity of silver nanoparticles in an intravenous 28 days repeated dose toxicity study in rats. Biomaterials, 34(33): 8333-8343. 